WellBeing International

WBI Studies Repository

2007

\title{
The Poor Contribution of Chimpanzee Experiments to Biomedical Progress
}

Andrew Knight

Animal Consultants International

Follow this and additional works at: https://www.wellbeingintlstudiesrepository.org/acwp_arte

Part of the Animal Experimentation and Research Commons, Animal Studies Commons, and the Design of Experiments and Sample Surveys Commons

\section{Recommended Citation}

Knight, A. (2007). The poor contribution of chimpanzee experiments to biomedical progress. Journal of Applied Animal Welfare Science, 10(4), 281-308.

This material is brought to you for free and open access by WellBeing International. It has been accepted for inclusion by an authorized administrator of the WBI Studies Repository. For more information, please contact wbisr-info@wellbeingintl.org.

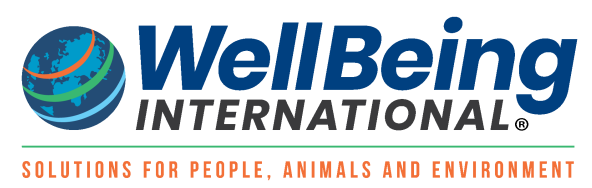




\title{
The Poor Contribution of Chimpanzee Experiments to Biomedical Progress
}

\author{
Andrew Knight, Animal Consultants International
}

\begin{abstract}
Biomedical research on captive chimpanzees incurs substantial nonhuman animal welfare, ethical, and financial costs that advocates claim result in substantial advancements in biomedical knowledge. However, demonstrating minimal contribution toward the advancement of biomedical knowledge generally, subsequent papers did not cite 49.5\% (47/95), of 95 experiments randomly selected from a population of 749 published worldwide between 1995 and 2004. Only 14.7\% (14/95) were cited by 27 papers that abstracts indicated described well-developed methods for combating human diseases. However, detailed examination of these medical papers revealed that in vitro studies, human clinical and epidemiological studies, molecular assays and methods, and genomic studies contributed most to their development. No chimpanzee study made an essential contribution, or, in most cases, a significant contribution of any kind, to the development of the medical method described. The approval of these experiments indicates a failure of the ethics committee system. The demonstrable lack of benefit of most chimpanzee experimentation and its profound animal welfare and bioethical costs indicate that a ban is warranted in those remaining countries-notably the United States- that continue to conduct it.
\end{abstract}

Chimpanzees are the species most closely related to humans and, consequently, the species most likely to be predictive of human outcomes when used in biomedical research. Hence, some advocate their use as models of humans in toxicity testing and research procedures that would be unethical to perform on people. The use of nonhuman primates (NHPs) such as chimpanzees is advocated for studies of hematology, immunology, pharmacology, virology (Herodin, Thullier, Garin, \& Drouet, 2005), neurotoxicology (Evans, 1990), and of potential bioterrorism agents such as anthrax, Ebola virus, Lassa virus, and the plague (Patterson \& Carrion, 2005). Chimpanzees are postulated to predict human pharmacokinetics-the time course of absorption, distribution, metabolism, and excretion of pharmaceutical agents-more accurately than other species in the laboratory: rats, dogs, and even other NHPs, making them the test model of choice for human toxicity testing and drug development (Wong et al., 2004). In a recent, prominent plea for increased funding for biomedical research on chimpanzees, VandeBerg et al. (2005) stated that such research has been of critical importance during our struggles against major human diseases. Similarly, British scientists recently called for the right to conduct such research on chimpanzeescontrary to the existing UK ban-in rare scenarios, such as the investigation of dangerous, emerging infectious diseases (Jha, 2006).

However, the similarities between humans and chimpanzees—when combined with the particularly high costs of their procurement and maintenance-also raise exceptional animal welfare, ethical, and financial concerns when these highly sentient creatures are experimented on in laboratories (Sauer, 2000; Thew, 2002). Some postulate that the genetic similarities of chimpanzees to humans-claimed to make them so useful as experimental models-are precisely what confers upon them a similar ability to suffer (de Waal, 1982, 1996; Goodall, 1986), making it unethical to confine and experiment upon them (Goodall \& Bekoff, 2002; Sauer, 2000; Thew, 2002). In addition, the high cost of chimpanzee research is increasingly problematic as competition for scarce research funds intensifies.

The first step in assessing the merits or otherwise of biomedical research on captive chimpanzees must be to obtain a clear picture of the disciplines examined by such research. The United States conducts more research on primates than any other country in the world-approximately 58,000 versus 11,000 annually-more than 5 times the number used in the entire European Union (Conlee, 2004). More than 2,200 chimpanzees were believed to be used in laboratories worldwide in 1993, more than $75 \%$ of whom were used in the United States (Stephens, 1995). Although the numbers had substantially fallen, 1,171 remained available for research in U.S. laboratories by 2005 (VandeBerg et al., 2005). 
To provide a recent assessment, Conlee, Haffeld, and Stephen, (2004) surveyed the Computer Retrieval of Information on Scientific Projects (CRISP) database, which contains U.S. federally funded, extramural, biomedical research projects; and PubMed (www.PubMed.com), a biomedical literature portal containing Medline, the U.S. National Library of Medicine's premier bibliographic database and related papers and citations. Based on 184 grant abstracts filed in CRISP and 89 biomedical journal articles cited in PubMed, some initial indications were gained of the disciplines investigated by U.S. chimpanzee research. A much larger survey, however, is required for definitiveness. Carlsson, Schapiro, Farah, and Hau (2004) surveyed 2,937 articles published in 2001 describing 4,411 NHP studies that used more than 41,000 primates worldwide; however, only a small minority of these used chimpanzees.

To gain a clear overview of the biomedical disciplines investigated via research on captive chimpanzees or chimpanzee tissues, I surveyed three major biomedical bibliographic databases and examined published studies conducted worldwide from 1995 to 2004. I focused on research on captive chimpanzees, particularly when invasive, because such research has raised the most concerns

To assess the utility of chimpanzee research in combating human diseases in particular, I determined the frequency with which these randomly selected chimpanzee studies had been cited by papers describing prophylactic, diagnostic, or therapeutic methods efficacious in combating human diseases.

\section{METHODS}

Three biomedical bibliographic databases were searched for published papers describing research conducted on captive chimpanzees or chimpanzee tissues from 1995 to 2004 inclusive: CAB Abstracts, the most comprehensive bibliographic database covering the applied life sciences, containing over 4.5 million records (Anonymous, n.d. a, b); EMBASE, the Excerpta Medica database, which is a biomedical and pharmacological database containing more than 10 million records (Anonymous, n.d. c); and Medline, the leading medical and allied health profession database, containing more than 12 million records (Anonymous, 2005). Jointly, these databases included more than 6,000 biomedical journals and thousands of other scientific documents sourced from more than 140 countries.

One of my key objectives was to determine the frequency with which chimpanzee research was cited by papers describing methods efficacious in combating human diseases; hence my survey was limited to these major databases likely to contain human medical papers. Primate-specific databases such as Primate Lit were excluded.

All titles, abstracts, and associated fields were searched for the following terms: chimpanzee, bonobo, Pan troglodytes, and Pan paniscus. In addition, the search was limited to documents with abstracts. Language or other limitations were not applied. To focus on research on captive chimpanzees, particularly when invasive, the following papers were included:

- $\quad$ studies of captive chimpanzees;

- $\quad$ studies of biometric information taken from captive chimpanzees, such as magnetic resonance imaging scans; and

- $\quad$ studies of fresh or preserved chimpanzee tissues, other than those specified.

The following papers were excluded:

- $\quad$ studies of free-living chimpanzees;

- veterinary medical case reports of the diagnosis, treatment, or post-mortem examination of naturally ill chimpanzees, whether or not in captivity;

- $\quad$ genome studies, other than of experimentally infected chimpanzees;

- $\quad$ studies of skeletal anatomy (which frequently used museum specimens);

- $\quad$ studies of cell lines (although I did include cell samples obtained from captive chimpanzees);

- $\quad$ studies of primate blood where the sources or species used were unspecified; and

- $\quad$ secondary analyses of data obtained in primary studies. 
A total of 749 chimpanzee studies were located that met these inclusion criteria. Resource constraints prevented detailed examination of all these studies; hence, an appropriate sample size was required from which to estimate the proportion of chimpanzee studies subsequently cited by other published papers. When calculating the sample size required, the relatively small population of 749 chimpanzee studies necessitated the use of the more accurate normal approximation to the hypergeometric distribution, rather than the normal approximation to the binomial distribution commonly used for large populations (Morris, n.d.; Green, 1982).

The hypergeometric formula used was:

$$
\text { Minimum sample size } n=\frac{N z^{2} p q}{\left(E 2(N-1)+z^{2} p q\right)}
$$

(Green, 1982; Guenther, 1973; Morris, n.d.)

where (a) $N=$ population size $=749$; (b) $z$ specifies the desired confidence interval $(\mathrm{Cl}), z=1.96$ for a $95 \% \mathrm{Cl}$; (c) $p$ and $q$ are population proportions, which were initially unknown, and which were both set to 0.5 to yield the most conservative possible outcomes; (d) $E=$ the desired accuracy of the sample proportions for the confidence interval chosen. For an accuracy of $+/-10 \%, E=0.1$.

Hence, the minimum sample size required to achieve $95 \%$ confidence intervals with an accuracy of at least plus or minus 10\%, for the sample proportions derived, was 86. An increased accuracy of plus or minus $5 \%$, for example, would have been preferable; however, this would have required a sample size of 255 , and detailed examination of a sample of this size was not possible due to resource constraints.

To select at least 86 viable chimpanzee studies for examination from the population of 749 , the "Research Randomizer" random number generator (www. randomizer.org) was used to generate a sample of 100 chimpanzee studies. For four of these studies, citing papers were not available through the bibliographic databases used, and one additional study was cited only by a paper for which no abstract was available. Resource constraints precluded initial screening of papers lacking abstracts; hence, these studies were excluded from further consideration, leaving 95 chimpanzee studies in the sample.

These 95 studies were examined to determine the proportion that were subsequently cited by papers of any kind and also by medical papers, specifically, that were published and included within these bibliographic databases by January 2006. Confidence intervals of $95 \%$ were then calculated for these proportions via the modified Wald method, available through the online statistical calculators at http://www.graphpad.com/quickcalcs/index.cfm, described in Agresti and Coull (1998) as providing more accurate results than the so-called exact method commonly used. The species and biomedical disciplines that were the focus of these citing papers were also ascertained.

Where abstracts of citing papers indicated the existence of prophylactic, diagnostic, or therapeutic methods with clear potential for combating human diseases, the complete medical papers were obtained and reviewed in detail to determine the contribution of the cited chimpanzee study to the development of the medical method described, in comparison with other cited sources of knowledge.

\section{RESULTS}

Bibliographic databases are constantly updated. As of August 28, 2005, 2,400 abstracts were located using the specified search terms. Of these, 749 were found to be studies of captive chimpanzees or chimpanzee tissues that met the inclusion criteria, of which 48.5\% (363/749) were biological experiments; 41.5\% (311/749) were virological experiments (Figure 1).

Biological investigations were conducted in nine disciplines, of which the most frequent (Figure 2) were cognition/neuroanatomy/neurology $(36.6 \%, 133 / 363)$ and behavior/communication $(20.7 \%, 75 / 363)$. 
FIGURE 1 Chimpanzee experiments 1995-2004 (total 749).

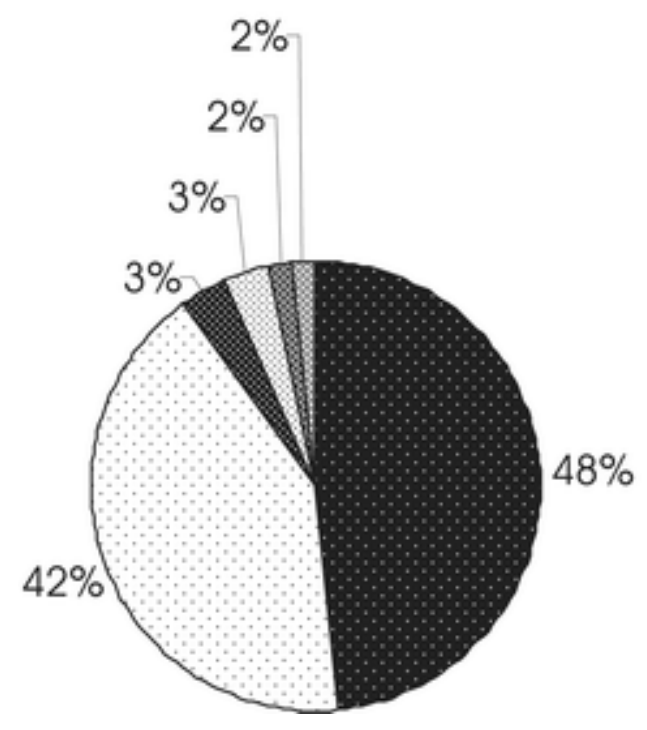

Biology (363)

Diseases: virology (311)

. Therapeutic investigations (26)

Diseases: parasitology (23)

Miscellaneous (14)

Diseases: other (12)

FIGURE 2 Biology experiments (363 of 749).

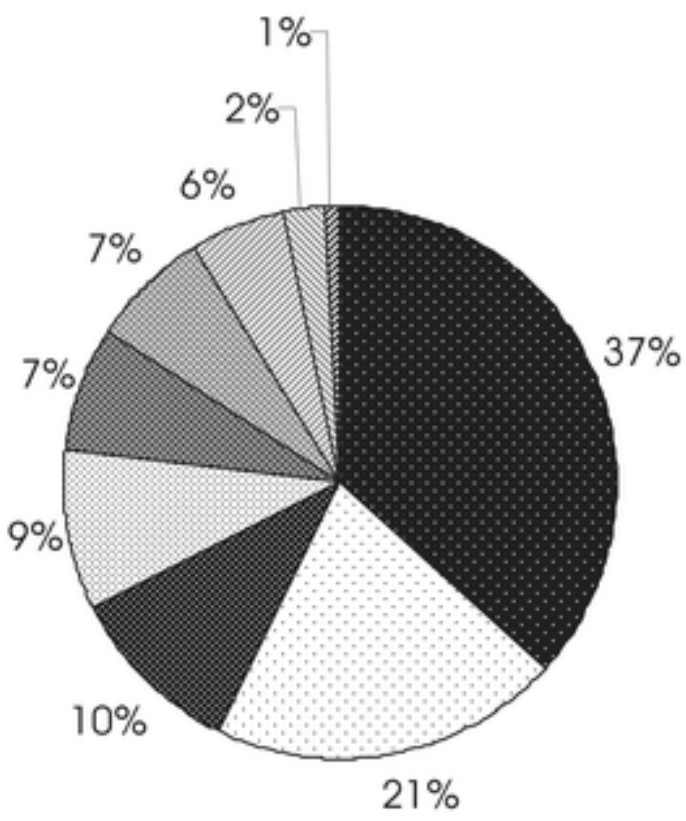

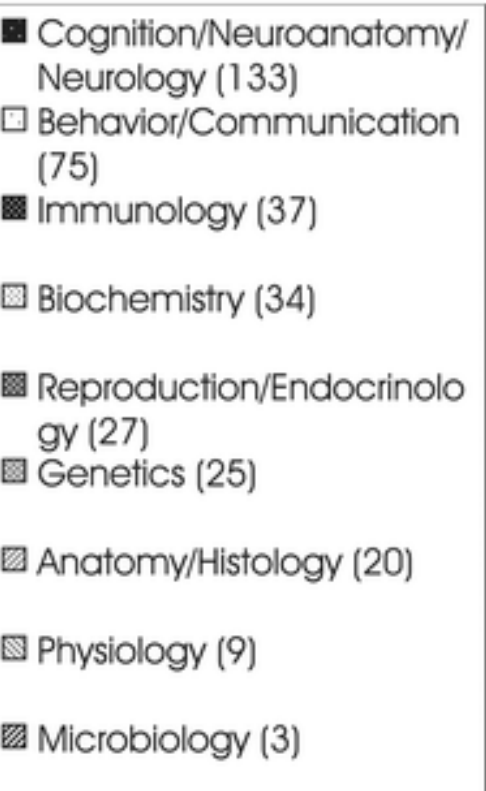

Virological investigations were conducted in 30 disciplines, of which the most frequent were hepatitis $\mathrm{C}$ virus (HCV) and human immunodeficiency virus (HIV), which both comprised 31.2\% (97/311) of all virology experiments (Figure 3).

Therapeutic investigations comprised 3.5\% (26/749) of all chimpanzee experiments, of which 61.5\% (16/26) investigated the pharmacological properties of various compounds. Other experiments included the testing of surgical techniques or prostheses, anesthesiological and toxicological investigations (Figure 4). 
FIGURE 3 Virology experiments (311 of 749).

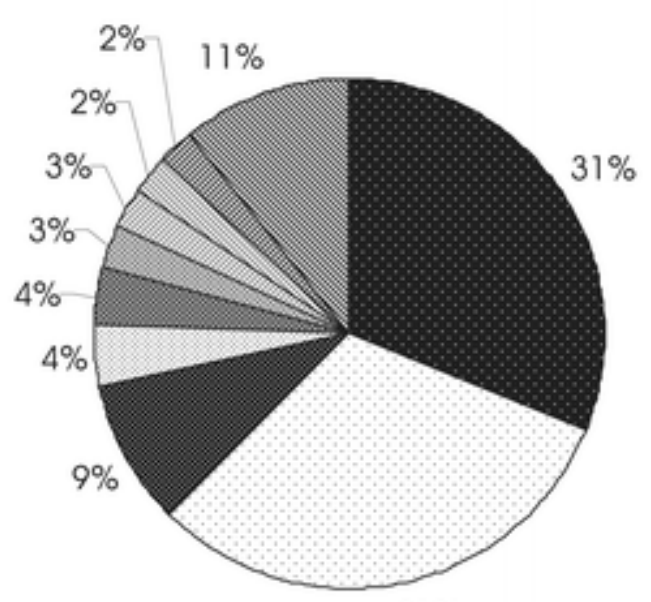

$31 \%$
: $\mathrm{HCV}(97)$

$\square$ HIV (97)

HBV (29)

$\square$ RSV (12)

鯧 HEV (11)

미닌 (9)

口 HIV \& SIV (8)

징 SIV (7)

四 $\operatorname{TV}(7)$

: 21 others (34)

Others: Six: FV. Four: HAV. Two each: GBV - B, HIV \& HV, IV, PV, Noroviuses. One each: Bacterioghages, Dengue v., Ebola v., HCMV, HGV, HMPV, H/S TLV, LCV, Papillomaviruses, RV2, Rhinowirus, VZV, WMHBV, Unspecified.

$H C V=$ hopatitis $C$ v., HV $=$ human immunodeficiency $v_{\text {., }} H B V=$ hepatitis $B$ v., RSV $=$ respiratory syncytial $v_{\text {., }}$ HEV $=$ hepatitis $E v$. $S T L V=\operatorname{simian} T$-cell lymphotropic v., SIV $=$ simian immunodeficiency v., TTV = transfusion-transmitted V., FV = foamy $v$ (human and simian FV. $H A V=$ hepatitis $A$ v., GBV-B $=G B$ virus $B, H V=$ herpes V., $I V=$ influenza $V_{.}, P I V=$ parainfluenza $V_{.}, H C M V=$ human cytomegalowius, HGV = hepatitis $G$ V. HMPV = human metapnoumovirus, H/S TLV = human/simian T-cell loukemis V. LCV = lymphocryptoviruses, RV2 = hadinovinus (or gamme-2-herpesvinus) genogroup 2, VZV = varicella-zoster V., WMHBV = woolly monkey hepatitis B $v$.

FIGURE 4 Therapeutic investigations (26 of 749$)$.

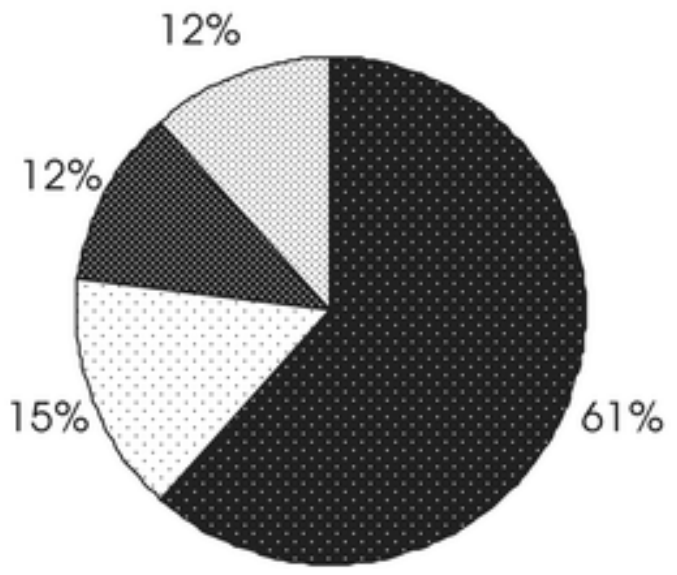

- Pharmacology (16)

$\square$ Surgical

techniques\Prostheses (4)

畻 Anesthesiology (3)

圆 Toxicology (3)

Parasitology experiments comprised 3.1\% (23/749) of all chimpanzee experiments. Eight parasitic species were investigated, of which the most frequent (Figure 5) were the malaria protozoa Plasmodium falciparum and $P$. ovale $(26.1 \%, 6 / 23)$, the roundworm Onchocerca volvulus $(21.7 \%, 5 / 23)$, and the flatworm Schistosoma mansoni $(17.4 \%$, 4/23).

Other diseases and miscellaneous experiments together comprised 3.5\% (26/749) of all chimpanzee experiments. The most frequent (Figure 6) were investigations of laboratory/husbandry techniques $(42.3 \%, 11 / 26)$ and endotoxemia $(30.8 \%, 8 / 26)$. Radiation studies were also conducted, and four other diseases were investigated, 
namely, benign prostatic hyperplasia, Creutzfeldt-Jakob disease, gastrointestinal bacteriology (Bacillus thuringiensis), and tuberculosis (Mycobacterium tuberculosis).

FIGURE 5 Parasitology experiments (23 of 749).

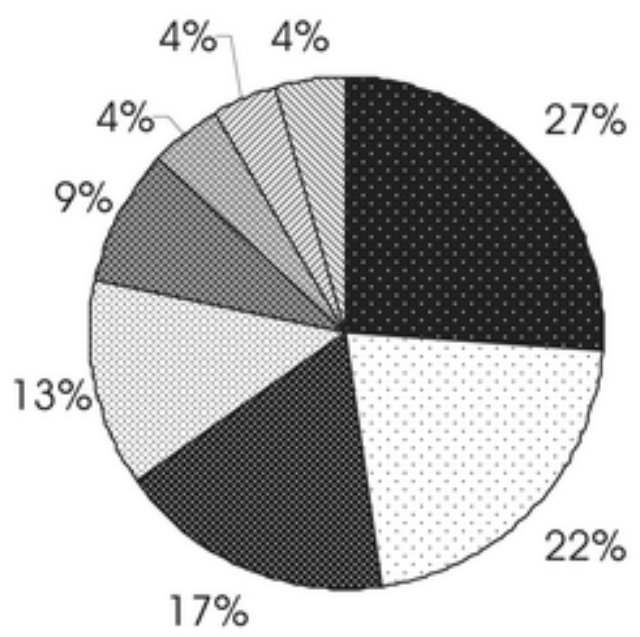

Plasmodium falciparum, P. ovale (malaria) (6) Onchocerca volvulus (roundworm) (5) 圆 Schistosoma mansoni (flatworm) (4)

Enterobius vermicularis, E. gregorii (pinworms) (3)

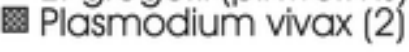
[: Balantodium coli (1) Mycoplasma spp. (1) Q Other (1)

FIGURE 6 Other diseases and miscellaneous experiments (26 of 749).

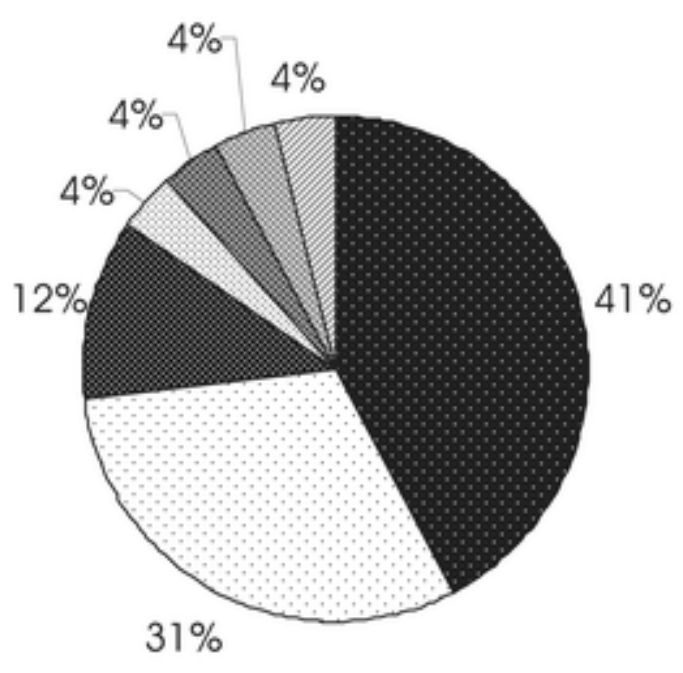

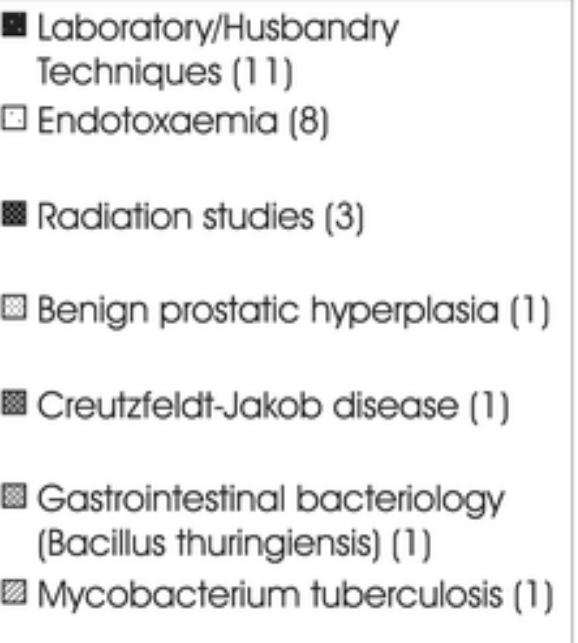

\section{Citations of Chimpanzee Studies}

Ninety-five chimpanzee studies were randomly selected from the population of 749 published between 1995 and 2004. Of these, $49.5 \%(47 / 95 ; 95 \% \mathrm{Cl}=39.6-59.4 \%)$ were not cited by any subsequent papers (Figure 7 ). 
FIGURE 7 Citations of 95 randomly selected published chimpanzee studies.

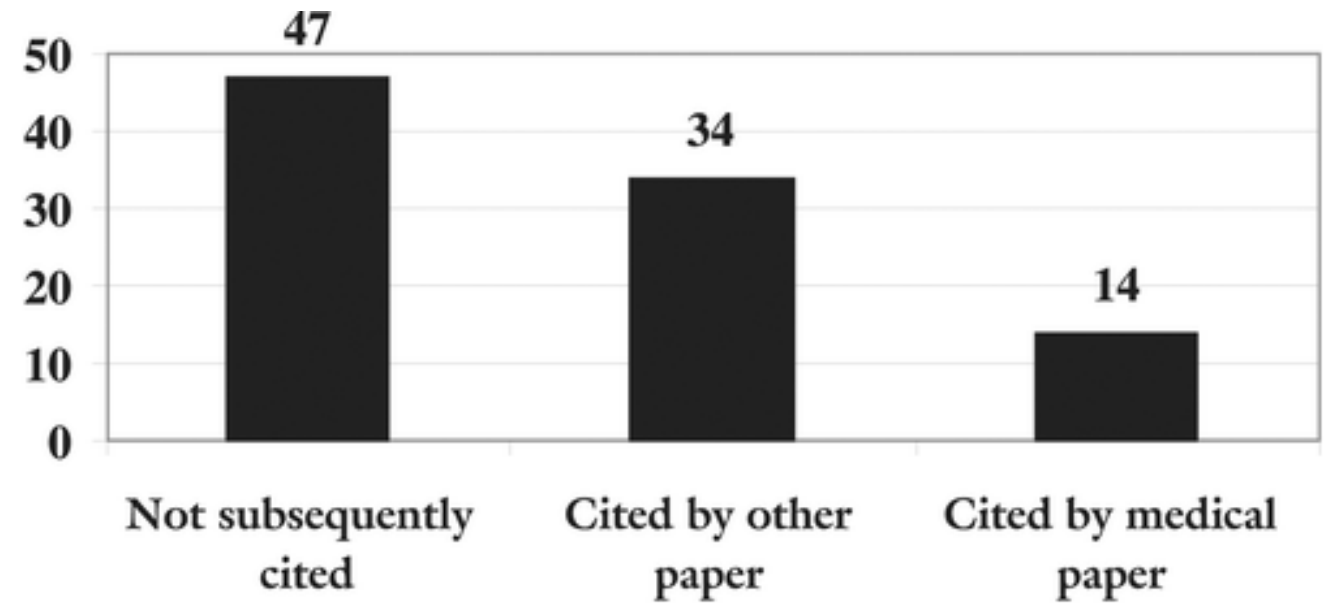

FIGURE 8 Chronological distribution of 48 cited chimpanzee studies.

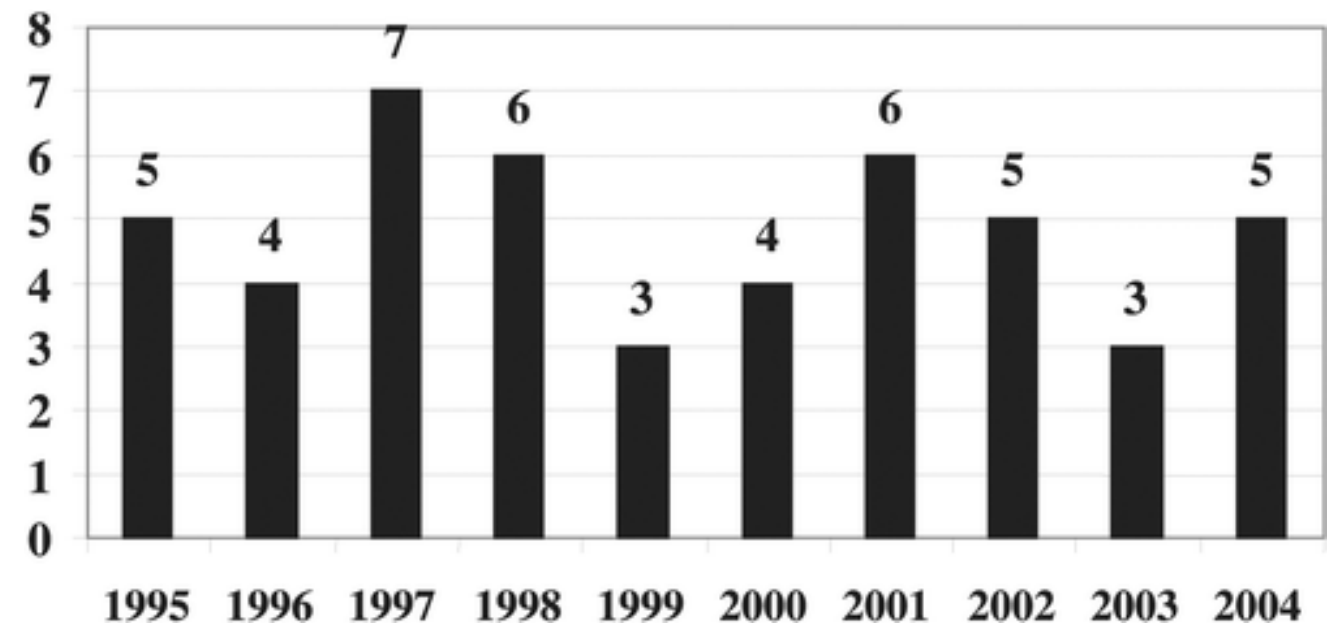

A total of 48 cited chimpanzee experiments were distributed fairly evenly across the decade (Figure 8).

These 48 chimpanzee studies were cited by 143 papers with abstracts and by 17 additional papers that lacked abstracts. Examination of these abstracts indicated that 35.8\% (34/95; 95\% Cl $=26.9-45.8 \%)$ of all chimpanzee studies were cited by 116 papers that clearly did not describe well-developed prophylactic, diagnostic, or therapeutic methods for combating human diseases. Some of these citing papers focused on humans in isolation or in combination with a variety of other species ranging from bacteria to elephants, including a large variety of primate species.

Various biological disciplines were investigated in these citing papers. Hepatitis viruses, cognition, and HIV-in that order-featured most prominently, although a substantial number of others were included (see Appendix).

Citing studies in this set that focused on humans as a primary subject examined a variety of disciplines other than pathology, or etiological or other aspects of human diseases. In a few cases, potential prophylactic, diagnostic, or 
therapeutic methods for combating human diseases were mentioned, however, all fell well short of being sufficiently developed for human use.

\section{Citing Medical Papers}

A total of 27 papers cited $14.7 \%(14 / 95 ; 95 \% \mathrm{Cl}=8.9-23.4 \%)$ of all chimpanzee studies. These studies described diagnostic methods (5) or prophylactic and/or therapeutic methods (22) for combating human diseases that abstracts indicated were fully developed-or in the latter stages of being developed-for human use. Diseases examined included cancer (non-specific), chronic obstructive pulmonary disease (COPD), Epstein-Barr virus (EBV), hepatitis viruses A through G (HAV through HGV), hepatocellular carcinoma (HCC), HIV, malaria, organ transplant rejection, respiratory syncytial virus (RSV), rheumatoid arthritis (RA), rhinovirus colds, systemic lupus erythematosus (SLE), and transmissible spongiform encephalopathies (TSEs) (Table 1).

\section{DISCUSSION}

Utility of Chimpanzee Studies in Advancing Biomedical Knowledge

On the face of it, studies of captive chimpanzees or chimpanzee tissues appear to have contributed to a large array of biomedical disciplines. However, not all knowledge has significant value or is worth the ethical and financial costs that may be incurred in gaining that knowledge. A universally accepted principle of sound experimental science involving human or nonhuman animal subjects is that the welfare-related, bioethical, financial, and other costs of a proposed experiment must be exceeded by the benefits reasonably expected to result. This is particularly important when potentially harmful research on non-consenting subjects is being contemplated, as is the case with much research on captive chimpanzees. In most research centers worldwide, institutional ethics committees are required by legislation to make such assessments and are expected to veto proposed experiments in which the benefits are not likely to exceed the costs.

Given that almost all of these 749 chimpanzee studies recently conducted worldwide would have been approved by ethics committees entrusted with engaging in precisely such deliberation, it is reasonable to expect that these experiments would have yielded significant benefits. However, this examination of 95 randomly selected chimpanzee studies revealed that half were not cited by any papers subsequently published and included in the comprehensive bibliographic databases examined. The year of publication did not appear to substantially affect this outcome, as citation frequencies were similar across the decade, with more recent papers cited approximately as often as older papers.

Citation frequencies are not, of course, a definitive indication of the benefits or lack thereof of scientific research. Uncited studies may also contribute to the advancement of biomedical knowledge through unpublished communications of results between scientists, the use of published studies without citation, and- potentially in the future-where recognition of the importance of results is delayed.

A potentially more accurate means of assessing the value of studies might be through detailed, individual examination of their aims, methods, results, and conclusions. However, resource constraints usually prevent such detailed examination of large numbers of studies. However, examination of smaller numbers may be feasible, once studies of interest are identified through initial screening measures, including citation analyses. In fact, precisely such a process occurred during this review. Such detailed individual assessments are, however, also more likely to vary between individuals.

Citation rates are not entirely objective either and may be affected by whether the study outcomes support the hypotheses under consideration, and by article length, number of authors, their country and university of affiliation (Leimu \& Koricheva, 2005).

The degree to which a journal is circulated and read within the scientific community may also affect the likelihood that papers published within it will be cited. Journal impact factors (JIFs) attempt to quantify such probabilities based largely on annual assessments of journal citation frequencies. Hence, it is possible that the disappointing citation rate of this sample of chimpanzee studies was due to their publication in lower impact-factor journals, when compared with publication norms. However, the randomness of the selection of this reasonably sized sample makes it likely that 
the impact factors of these journals were broadly similar to those of the larger population of journals in which the entire population of chimpanzee studies were published. It may be true that chimpanzee studies are generally published in journals with lower JIFs; however, this would also be a reflection of the lack of importance accorded to these studies and a potential cause of their lowered citation rates.

TABLE 1 Twenty-Seven Medical Papers Citing Chimpanzee Studies

\begin{tabular}{|c|c|c|c|c|c|c|}
\hline Paper & $\begin{array}{l}\text { Human Disease } \\
\text { Investigated }\end{array}$ & $\begin{array}{l}\text { Medical Approach: } \\
\text { Prohylactic, } \\
\text { Diagnostic, } \\
\text { Therapeutic }\end{array}$ & Citing Medical Paper & Paper Type & $\begin{array}{l}\text { Review } \\
\text { Refs }\end{array}$ & $\begin{array}{l}\text { Cited Chimpanzee } \\
\text { Study }\end{array}$ \\
\hline 1 & Cancer (non-specific) & Ther & Tong \& Stone (2003) & Review & 155 & Brams et al. (2001) \\
\hline 2 & COPD & Prophy & Suzuki et al. (2001) & Research & & Huguenel et al. (1997) \\
\hline 3 & EBV & Prophy & Khanna et al. (1999) & Review & 112 & Bertoni et al. (1998) \\
\hline 4 & HAV \& HBV & Prophy & Koff (2002) & Review & 85 & Ogata et al. (1999) \\
\hline 5 & HAV-HGV & Prophy, Ther & Regev \& Schiff (1999) & Review & 71 & Mast et al. (1998) \\
\hline 6 & HBV & Prophy & McMahon et al. (2005) & Research & & Ogata et al. (1999) \\
\hline 7 & HBV & Prophy, Ther & Karayiannis (2003) & Review & 300 & Pancholi et al. (2001) \\
\hline 8 & $\mathrm{HCV}$ & Diag & Hüssy et al. (1997) & Research & & Wang et al. (1996) \\
\hline 9 & $\mathrm{HCV}$ & Ther & Feld \& Hoofnagle (2005) & Review & 91 & Bigger et al. (2001) \\
\hline 10 & $\mathrm{HCV}$ & Ther & Nakano et al. (1999) & Research & & Wang et al. (1996) \\
\hline 11 & HEV & Prophy & $\begin{array}{l}\text { Worm \& Wirnsberger } \\
(2004)\end{array}$ & Review & 133 & Mast et al. (1998) \\
\hline 12 & HEV & Diag & Obriadina et al. (2002) & Research & & Mast et al. (1998) \\
\hline 13 & $\mathrm{HCC}$ & Diag & Kim \& Wang (2003) & Review & 81 & Bigger et al. (2001) \\
\hline 14 & HIV & Prophy, Ther & Armbruster et al. (2002) & Research & & Conley et al. (1996) \\
\hline 15 & HIV & Prophy, Ther & Armbruster et al. (2004) & Research & & Conley et al. (1996) \\
\hline 16 & HIV & Prophy, Ther & $\begin{array}{l}\text { Bardsley-Elliot \& Perry } \\
(2000)\end{array}$ & Review & 130 & Grob et al. (1997) \\
\hline 17 & HIV & Prophy & Hone et al. (2002) & Review & 108 & Conley et al. (1996) \\
\hline 18 & HIV & Prophy, Ther & $\begin{array}{l}\text { Sleasman \& Goodenow } \\
(2003)\end{array}$ & Review & 93 & Conley et al. (1996) \\
\hline 19 & HIV & Diag & Yang et al. (1998) & Research & & Conley et al. (1996) \\
\hline 20 & HIV & Ther & Gallo (2002) & Review & 258 & Goh et al. (1998) \\
\hline 21 & Malaria & Prophy & Moore \& Hill (2004) & Review & 104 & Pancholi et al. (2001) \\
\hline 22 & Organ transplant rejection & Ther & Matthews et al. (2003) & Review & 87 & Newman et al. (2001) \\
\hline 23 & RSV & Prophy & Kneyber \& Kimpen (2002) & Review & 150 & Crowe et al. (1999) \\
\hline 24 & RA & Ther & Hepburn et al. (2003) & Research & & Newman et al. (2001) \\
\hline 25 & Rhinoviral colds & Prophy & Turner et al. (1999) & Research & & Huguenel et al. (1997) \\
\hline 26 & SLE & Ther & Gescuk \& Davis (2002) & Review & 77 & Brams et al. (2001) \\
\hline 27 & TSE & Diag & Brown (2005) & Review & 26 & $\begin{array}{l}\text { Cervenakova et al. } \\
(2003)\end{array}$ \\
\hline
\end{tabular}

Note. $C O P D=$ chronic obstructive pulmonary disease, $E B V=$ Epstein-Barr virus, $H A V-H G V=$ hepatitis viruses $A$ through $G, H C C=$ hepatocellular carcinoma, HIV = human immunodeficiency virus, $R S V=$ respiratory syncytial virus, $R A=$ rheumatoid arthritis, SLE = systemic lupus erythematosus, $T S E=$ transmissible spongiform encephalopathy. 
On the other hand, Seglen (1989) found that citation frequencies of articles published by individual authors or research groups correlated extremely poorly with their corresponding JIFs. Seglen consequently concluded that JIFs are unsuitable as an indicator of scientific quality. Hence, it appears likely that the disappointing citation rates of chimpanzee experiments are indeed a reflection of their lack of scientific value rather than the result of a very large number of consistently unfortunate journal choices.

Despite their limitations, citation frequencies generally provide a quantifiable and reasonably objective approximation of utility or lack thereof. Research that makes a significant contribution to a field-such as by confirming or refuting hypotheses-is very likely to be cited by future papers, as is research that produces interesting or controversial outcomes. On the other hand, research that is inconclusive or of little interest or significance is much less likely to be cited.

The disappointing citation rate of these chimpanzee studies is therefore cause for considerable concern. Although uncited studies may contribute to the advancement of biomedical knowledge through various means, it is unreasonable to conclude that a large number of studies made a significant contribution-if none were cited by any future publication, as occurred for half of these randomly selected chimpanzee studies.

Given that research of lesser significance is not published at all, these published chimpanzee experiments can be assumed to be those with the greatest potential for advancing biomedical knowledge. Consequently, these results indicate that the majority of captive chimpanzee research generates data of questionable value, which makes little obvious contribution toward the advancement of biomedical knowledge.

Ethics committees are generally required by legislation, and expected by society, to allow only those experiments in which the benefits are likely to exceed the costs. The welfare-related, bioethical and financial costs integral to chimpanzee experimentation are profound (Anonymous, 1995; Balls, 1995; Langley, 2006; Scharmann, 2000; Smith \& Boyd, 2002). The benefits accruing from these chimpanzee experiments, on the other hand, were clearly questionable. Because very few research fields incur similar costs, even favorable citation rates-compared to other fields of research-would not alter this assessment. Therefore, the approval of large numbers of these experiments, despite their questionable value, indicates a widespread failure of the ethics committee system.

\section{Utility of Chimpanzee Studies in Combating Human Diseases}

Most would consider that the greatest justifications for research on captive chimpanzees involve attempts to advance human health. Advocates of such research claim its critical importance during our struggles against major human diseases (VandeBerg et al., 2005). However, only $14.7 \%$ of these randomly selected chimpanzee studies were cited by a total of 27 papers that abstracts indicated might describe well-developed methods for combating human diseases.

As stated, citation rates are not a definitive indication of utility or lack thereof. Chimpanzee studies may have contributed to medical advances through various indirect means, such as by stimulating investigation of certain lines of inquiry in humans, although it is unlikely that any medical papers subsequently published would not cite the chimpanzee studies that provided such inspiration. Alternatively, chimpanzee studies may have contributed to investigations of disease etiology or to papers describing prophylactic, diagnostic, or therapeutic methods for combating human diseases in early stages of development-although potential human benefits, in such cases, remain speculative.

However, it is reasonable to expect that if chimpanzee research had truly been of critical importance during struggles against major human diseases, as claimed by advocates, such chimpanzee studies would be cited by papers describing methods efficacious in combating those diseases. The only remaining possibility is that none of the struggles - to which chimpanzee research purportedly made major contributions-resulted in effective, published solutions.

In fact, some papers describing well-developed prophylactic, diagnostic, or therapeutic methods for combating human diseases cited chimpanzee studies. The contribution of the cited chimpanzee study to these papers, in comparison to other cited sources of knowledge, deserves closer scrutiny. 


\section{Sources Contributing to Medical Papers}

Twenty-seven medical papers cited randomly selected chimpanzee studies. Methods that featured frequently in the development of the medical methods described included (a) in vitro studies, (b) human clinical and epidemiological studies, (c) molecular assays and methods, and (d) genomic studies. Four methods, featuring particularly prominently in various cases, were used in at least 18 papers:

1. In vitro studies, such as of human T-cells, HeLa cells, human respiratory epithelium (embryonic lung fibroblasts), human adenoid explants, lymphoblastoid and rodent cells lines, were used in at least 18 papers;

2. Human clinical and epidemiological studies were used in at least 15 and 6 medical papers, respectively;

3. Molecular methods, such as immune electron microscopy, radioimmunoassay, polymerase chain reaction (PCR), enzyme-linked immunosorbent assay (ELISA), Western blot, and several assays designed for the diagnosis of TSEs: a combination of competitive antibody capture and capillary electrophoresis, conformation-dependent immunoassay, screening for intensely fluorescent targets, and an immuno-PCR assay, were used in at least 8 medical papers; and

4. Genomic techniques_such as serial analysis of gene expression and microarray analysis of viral genomes, for example; suppression subtractive hybridization; representational difference analysis; and differential display_featured more prominently in 4 medical papers.

Several viral studies used E. coli and baculoviruses in conjunction with Sf9 insect cells as vectors for viral delivery and expression.

Chimpanzee studies were, of course, cited by all the medical papers. Additional animal models were cited more prominently in five medical papers. Models included genetically modified and unmodified mice, rats, hamsters, guinea pigs, sheep, goats, cows, mink, woodchucks, and NHPs (baboons, orangutans, cynomolgus monkeys, and rhesus macaques). Several of these species were cited in only one paper (Brown, 2005) that described diagnostic methods for combating TSEs, either as sources or recipients of TSE-infected tissues.

A detailed examination of the contributions-or otherwise-of animal models other than chimpanzees was beyond the scope of this study. However, as Brown (2005) aptly put it, “... it is always problematic to what extent such models reflect the human situation" (pp. 66, 67).

\section{Contributions Made by Chimpanzee Studies}

The randomly selected chimpanzee studies proved to be of peripheral importance to most of these medical papers for a variety of reasons. Of these papers, 63.0\% (17/27) were wide-ranging reviews of 26-300 (median 104) references, to which the cited chimpanzee study made a very small contribution. In 12 cases (Table 1: papers 5, 8$13,16,20,24-25,27)$, the chimpanzee studies appeared redundant because humans or human sera were studied concurrently or because they served only to confirm previous human observations. In 7 cases (Table 1: papers 2, 2227), the method explored in the cited chimpanzee study was not developed further, sometimes because later clinical trials in humans failed to demonstrate safety or efficacy, contrary to positive chimpanzee results. In 5 cases (Table 1 : papers $3-4,13,21,25)$, the chimpanzee study examined a disease or method of only peripheral relevance to the medical method described. In 3 cases (Table 1: papers 2, 17, 19), the chimpanzee study merely illustrated a historical finding or was cited only during historical discussions of attempts to combat the disease in question. In another 3 cases (Table 1: papers $7,17,26$ ), the chimpanzee studies yielded results inconsistent with data from other NHP studies; in 2 cases (Table 1: papers 18, 24), they yielded results inconsistent with human data. In 2 more cases (Table 1: papers 8, 10), only the human outcomes from concurrent human studies-described within the cited chimpanzee studies-were discussed. In 1 case (Table 1: paper 12), the chimpanzee study may have helped establish the need for a new diagnostic method but did not contribute further to its development.

Five chimpanzee studies were cited by more than one medical paper and deserve closer examination. Bigger, Brasky \& Lanford's (2001) paper on the effects of HCV in chimpanzees served only to confirm what had already been observed in earlier human studies cited by Feld \& Hoofnagle's (2005) paper on therapeutic methods for combating HCV (Table 1: paper 9), and was of peripheral relevance to Kim \& Wang's (2003) paper describing a diagnostic method for the detection of HCC (Table 1: paper 13). 
Conley et al.'s (1996) study of the prophylactic use of human monoclonal antibodies (hMAbs) in chimpanzees challenged with HIV-1 was cited by five medical papers. In two studies of prophylactic and therapeutic methods for combating HIV (Armbruster et al., 2002, 2004), positive prior results in the cited chimpanzee study appeared to suggest a potential field of further development with respect to hMAb choices used in combination prophylactic and therapeutic regimes (Table 1: papers 14-15). The cited chimpanzee study did not, however, play an integral role in the citing studies, the purpose of which was to examine the safety, immunogenicity, and pharmacokinetics of hMAb protocols in clinically healthy HIV-1-infected human volunteers. In papers by Hone et al. (2002) and Yang, D'Souza, and Vyas (1998), describing the development of a diagnostic method and vaccines, respectively, for combating HIV, the cited chimpanzee study served only to demonstrate that effective HIV antibodies can indeed neutralize HIV in chimpanzees to varying degrees, although conflicting results were observed in 6 other NHP studies cited by Hone et al. (Table 1: papers $17 \&$ 19). The cited chimpanzee study did not otherwise contribute to the development of these diagnostic and prophylactic methods. The contribution of this study to the development of prophylactic and therapeutic methods for combating HIV, reviewed by Sleasman and Goodenow (2003), was similarly limited by inconsistency with other cited human data (Table 1: paper 18).

Mast, Alter, Holland, and Purcell's (1998) paper describing the poor sensitivity, concordance, and variable efficiency of previously available HEV assays in chimpanzees, particularly against different HEV strains, was cited by Obriadina et al.'s (2002) paper describing the development of a diagnostic technique for the detection of HEV (Table 1: paper 12), and by Regev and Schiff's (1999) review of prophylactic and therapeutic options for combating HAV, HBV, HCV, HEV, HGV and transfusion-transmitted virus (Table 1: paper 5). The chimpanzees in this study were used as both positive and negative controls. However, their use was redundant, for more relevant positive and negative human controls in the form of human sera were concurrently available. In addition, one of Mast et al.'s key outcomes was the highly discrepant, existing HEV assay results from U.S. blood donors that were presumed HEV negative, necessitating great caution when interpreting positive assay results. This outcome relied exclusively on human results.

Newman et al.'s (2001) paper demonstrating the safety and efficacy of Keliximab-a primatized IgG1 anti-CD4 mAb-in modulating T-cell receptor responsiveness in chimpanzees, was cited by two medical papers. In Matthews, Ramos, and Bluestone's (2003) review of therapeutic strategies designed to combat organ transplant rejection, it was hoped that the targeting of cellular receptors might result in T-cell inactivation, thereby delaying allograft rejection; Tcell activation is central to the inflammation and tissue damage that results in such rejection (Table 1: paper 22). Hepburn, Totoritis, and Davis (2003) also described their clinical trial of Clenoliximab, an anti-CD4 mAb proposed for the treatment of RA (Table 1: paper 24). However, a later Phase II human clinical trial of an analogue drug (Zanolimumab) failed to demonstrate efficacy at combating RA, resulting in discontinuation of the development of this drug for RA patients-also casting doubts upon the efficacy of anti-CD4 mAbs in combating allograft rejection.

A paper describing chimpanzee studies of DNA-based vaccines (Pancholi et al., 2001) was cited both by Karayiannis's (2003) review of the prophylactic and therapeutic options available for combating HBV (Table 1: paper 7), and by Moore and Hill's (2004) review of strategies for the development of a malaria vaccine (Table 1: paper 21). In the former case, inconsistency with other chimpanzee and NHP results limited the utility of the cited chimpanzee study; in the latter case, the disease and vaccination strategies explored were too distant from those investigated in the cited chimpanzee study to accord it more than tenuous relevance.

Wang, Brotman, Andrus \& Prince's (1996) study of the reactivity of humans and chimpanzees to various epitopes of HCV H-strain structural proteins was cited by both Hüssy et al.'s (1997) paper investigating a diagnostic method for HCV (Table 1: paper 8), and by Nakano et al.'s (1999) paper investigating therapeutic options for HCV (Table 1: paper 10). In both cases, however, only the human outcomes concurrently described within this chimpanzee study contributed to the citing medical paper. In fact, the cited chimpanzee study served mainly to illustrate the differences in the immune responses of humans and chimpanzees to HCV.

Several authors of human medical papers or cited chimpanzee studies identified potential problems regarding attempts to extrapolate chimpanzee results to human outcomes. Wang et al. (1996) identified key differences between the immune responses of humans and chimpanzees to HCV infection. In their study of prophylactic methods for combating EBV, Khanna, Moss, and Burrows (1999) stated, "It would be a mistake to assume that experimental results obtained in these ... primate models had direct relevance to vaccine formulations that might offer protection 
against infectious mononucleosis [one of the main targets for a vaccine]" (p. 54).When commenting on the failure of a test drug to demonstrate efficacy at combating (T-cell dependent) RA in a phase II clinical trial—despite prior efficacy of an analogue drug in modulating T-cell receptor responsiveness in chimpanzees, and other clinical failures contrary to animal in the laboratory successes-Matthews et al. (2003) stated, "... results to date illustrate the profound difficulties in translating animal model success to the clinical arena" (p. 798). Development of this test drug for RA patients was discontinued. In his review of prophylactic methods for combating HAV and HBV, Koff (2002) described the cited chimpanzee study as potentially complicating our understanding of escape viruses.

Factors Limiting the Medical Utility of Chimpanzee Studies

Although just under $15 \%$ of these chimpanzee studies were cited by 27 papers that abstracts indicated might describe well-developed methods for combating human diseases, detailed individual examination of these papers revealed that in vitro studies; human, clinical, and epidemiological studies; molecular assays and methods; and genomic studies contributed most to the development of the medical methods described. Studies in a variety of animal species other than chimpanzees were cited by at least 5 papers, but some authors questioned their applicability to human outcomes. The chimpanzee studies cited by these 27 medical papers did not appear to contribute substantially to the development of the medical methods under consideration.

These results suggest a lack of utility of chimpanzees as an experimental model for combating human diseases. On the face of it, this appears contrary to expectations, given the genetic similarities of chimpanzees to humans. Our two species shared a common ancestor just 5-7 million years ago-a very short time span in phylogenetic terms. A 2005 draft of the chimpanzee genome confirmed it to be $98.77 \%$ identical to the human genome in terms of base pairs (The Chimpanzee Sequencing and Analysis Consortium, 2005); insertions, deletions, and consequent misalignments, however, raise the total estimated difference to around 4-5\% (Britten, 2002; Varki \& Altheide, 2005).

Although a minority of these genetic differences between humans and chimpanzees lie within structural genes, most are now known to lie within the regulatory regions of our DNA. In regulating the activities of structural genes, regulatory genes can exert an "avalanche" effect upon hundreds of other genes. Consequently, a small difference may have profound effects (Bailey, 2005). Striking differences have been found in the levels of gene expression between chimpanzees and humans in the brain and liver (Ruvolo, 2004).

Although chimpanzees and humans differ in only 4-5\% of their DNA, that difference is sufficiently important to result in a difference of about $20 \%$ in protein expression (Glazko, Veeramachaneni, Nei, \& Makalowski, 2005), resulting in marked phenotypic differences between the species: (a) differences in the susceptibility to, etiology and progression of various diseases; (b) differences in absorption, tissue distribution, metabolism, and excretion of chemotherapeutic agents; and (c) differences in the toxicity and efficacy of pharmaceuticals (Bailey 2005).

Furthermore, the tissue responses to disease agents and test chemotherapeutics in chimpanzees in the laboratory are likely to be distorted by the neurological, endocrinological, and immunological abnormalities that result from the variety of stresses these chimpanzees commonly endure. These include standardized small, barren, laboratory housing; immobilization; isolation; or-less frequently-overcrowding; aggression from fearful or frustrated cage mates; trauma; chronic boredom; and a variety of stressful laboratory procedures (Fouts, 1995).

The substantial differences in protein expression between chimpanzees and humans and the further distortions of normal physiology that result from the stressful laboratory environment and procedures common to chimpanzee experimentation are the most likely causes of the observed lack of utility of chimpanzee research in the development of prophylactic, diagnostic, and therapeutic methods efficacious in combating human diseases.

\section{Study Limitations}

As stated, one of my key objectives was to determine the frequency with which chimpanzee research was cited by papers describing methods efficacious in combating human diseases; hence, my survey was limited to major biomedical bibliographic databases likely to contain human medical papers. Primate-specific databases such as Primate Lit were excluded. It is possible that greater non-medical utility of these randomly selected chimpanzee studies might have been evident via such additional database searches. However, the databases searched included the most comprehensive databases covering the applied life sciences. They contained in excess of 12 million 
records, 6,000 biomedical journals, and thousands of other scientific documents sourced from over 140 countries. Hence, any discrepancies are unlikely to be large, and no contributions of major importance are likely to have been excluded by my review.

Initial indications of the medical utility of these chimpanzee studies were assessed by examining the 160 papers that cited 50.5\% (48/95) of these studies. Of these 160 citing papers, 143 had abstracts, and 17 (10.6\%) lacked them. Due to resource constraints, these 17 papers were not examined. Hence, it is possible that the true number of chimpanzee studies cited by medical papers may have been slightly higher than indicated by my results. However, any such discrepancy is likely to be small; $18.9 \%(27 / 143)$ of the citing papers, for which abstracts were available, proved to be medical papers of interest. If $18.9 \%$ of the 17 unexamined papers had been of similar interest, approximately only 3 additional medical papers would have resulted, citing-at most-a very few additional chimpanzee studies.

Approximately $15 \%$ of these chimpanzee studies were cited by papers that abstracts indicated might describe welldeveloped methods for combating human diseases. However, detailed examination of the complete medical papers revealed that their contributions-compared to other cited sources of knowledge-were small. Although these results clearly demonstrate that chimpanzee studies do not generally make important contributions to the development of methods efficacious in combating human diseases, they cannot provide conclusions on exceptional cases. Assessing contributions of any exceptionally valuable chimpanzee studies would require their identification based on citation frequencies, publication in leading journals, and other indicators of possible value-not on random selection.

Precisely such a strategy was recently employed by Hackam \& Redelmeier (2006), who sought to assess the clinical utility of very highly cited animal experiments-without species limitation-published in the seven leading scientific journals. Ranked by citation impact factor, these journals regularly publish original animal studies. Of 76 animal studies located with a median citation count of 889 (range: $639-2,233)$, only $36.8 \%(28 / 76)$ were replicated in human, randomized trials; $18.4 \%$ (14/76) were contradicted by randomized trials; and 44.7\% (34/76) had not been tested. Ultimately, only $10.5 \%$ (8/76) of these medical interventions were subsequently approved for use in human patients. No similar study focusing specifically on captive chimpanzee research has yet been published.

\section{CONCLUSIONS}

The advanced sensory, cognitive, communicative, and social abilities of chimpanzees (Byrne, 1998; de Waal, 1982, 1996; Goodall, 1986, 1995; Hare, Call, Agnetta, \& Tomasello, 2000; Tomasello, Call, \& Hare, 2003; Whiten \& Byrne, 1988) also confer upon them a profound ability to suffer when born into unnatural captive environments or captured from the wild-as many older research chimpanzees once were-and when subsequently subjected to confinement, social disruption, and involuntary participation in potentially harmful biomedical research.

Justifications, proposed by advocates for such research, rely upon the critical contributions advocates claim the research has made to the advancement of biomedical knowledge-in particular, toward combating major human diseases. However, this systematic review of 95 randomly selected studies of captive chimpanzees, conducted during a recent decade, revealed that half were not cited by any papers subsequently published and included within the comprehensive bibliographic databases examined. The review indicated that the studies generated data of questionable value that made little obvious contribution to the advancement of biomedical knowledge. Given that research of lesser significance is not published, these results indicate that the majority of chimpanzee experiments generate data of questionable value.

In addition, closer examination failed to identify any chimpanzee studies that made an essential contribution or-in a clear majority of cases-a significant contribution of any kind to papers describing well-developed prophylactic, diagnostic, or therapeutic methods for combating human diseases.

Despite the low utility of chimpanzee experiments in advancing human healthcare indicated by these results, it remains true that chimpanzees are the species most closely related to human beings. Hence, it is highly likely that other species are even less efficacious when used as experimental models of humans in biomedical research and toxicity testing. Given the many millions of other species used annually for these purposes (particularly in the case of rodents); the profound ethical and financial costs incurred as a result; and the adverse consequences for human 
health-if other, potentially more efficacious research models are consequently deprived of funding-systematic reviews of the utility of other laboratory species in advancing human healthcare are also urgently warranted. These reviews ought to be conducted by government agencies with oversight for animal research and by others with similar responsibilities within the commercial and academic sectors.

Furthermore, almost all these chimpanzee experiments-given the profound animal welfare, ethical, and financial costs integral to chimpanzee experimentation-would have been approved by an institutional ethics committee, required by legislation to approve only those experiments likely to result in substantial benefits. Although the concept of ethical review is sound, these results demonstrate that its implementation is presently flawed. This flaw has resulted from over-reliance on the assumption, in the absence of supportive evidence, that animal experiments are likely to be of substantial use in advancing biomedical progress.

This systematic study and others, some of which have examined hundreds of randomly selected animal experiments, have demonstrated that animals-to justify their widespread use as experimental models of humans-are not sufficiently predictive of the progression of human diseases, human toxicity, or responses to chemotherapeutic agents (Bailey, Knight, \& Balcombe, 2005; Curry, 2003; Hackam \& Redelmeier, 2006; Horn, de Haan, Vermeulen, Luiten, \& Limburg, 2001; Jonas, Aiyagari, Vieira, \& Figueroa, 2001; Knight, Bailey, \& Balcombe, 2006a, 2006b; Lazzarini, Overgaard, Conti, \& Shirtliff, 2006; Lindl, Völkel, \& Kolar, 2005, 2006; O'Collins et al., 2006; Perel et al., 2007; Pound, Ebrahim, Sandercock, Bracken, \& Roberts, 2004).

Twenty published systematic reviews examining the human clinical utility of animal experiments were identified during a recent, comprehensive literature search (Knight, 2007). Authors concluded that animal models were significantly useful in contributing to the development of clinical interventions or substantially consistent with clinical outcomes in only two cases-one of which was contentious. Included were reviews of the clinical utility of animal experiments expected by ethics committees to lead to medical advances and of highly-cited experiments published in major journals. Seven additional reviews failed to clearly demonstrate utility in predicting human toxicological outcomes such as carcinogenicity and teratogenicity.

Clearly, the assumption that animal experiments are likely to be of substantial use in advancing biomedical progress is not supported by most existing evidence. This systematic review has demonstrated that this assumption is no more correct when applied to chimpanzee experiments. On the other hand, the animal welfare, ethical, and financial costs of chimpanzee experimentation are particularly high. By approving these experiments on the basis of unfounded assumptions about their likely benefits, the ethics committees responsible failed in their duty to society and to the animals they were charged with protecting.

Unless and until credible evidence emerges demonstrating that biomedical research on captive chimpanzees is truly likely to provide benefits in excess of its profound costs, it seems eminently reasonable to join numerous experts (Anonymous, 1995; Balls, 1995; Langley, 2006; Scharmann, 2000; Smith \& Boyd, 2002) in calling for the banning of such research in those remaining countries-notably the United States-that continue to conduct it.

\section{ACKNOWLEDGMENTS}

This research was partly funded by the New England Anti-Vivisection Society, Boston, and by a monetary prize awarded by the German Animal Welfare Federation, Neubiberg, for previous research on animal experimentation. These sponsors had no substantial role in the design and conduct of the study; collection, management, analysis, and interpretation of the data; or the preparation, review, or approval of this manuscript. I thank Dr. Jarrod Bailey and Dr. Jonathan Balcombe for their assistance during the 27 medical paper reviews and Dr. Lawrence D'Antonio for his assistance with the statistical analysis.

\section{REFERENCES}

Agresti, A., \& Coull, B. A. (1998). Approximate is better than "exact" for interval estimation of binomial proportions. The American Statistician, 52, 119-126. 
Anonymous (1995). Resolution. In Poor model man: Experimenting on chimpanzees: Proceedings of the First PACE (People Against Chimpanzee Experiments) conference on the use of chimpanzees in biomedical research. Alternatives to Laboratory Animals, 23, 571.

Anonymous (2005). Pubmed overview. Retrieved August 11, 2005, from http://www.ncbi.nlm.nih. gov/entrez/query/static/overview.html

Anonymous (n.d. a). CAB abstracts. Retrieved August 11, 2005, from http://www.cabi-publishing .org/pdf/CABAbstracts/CABAbs.pdf

Anonymous (n.d. b). Database coverage. Retrieved August 11, 2005, from http://www.cabi-pub lishing.org/AbstractDatabases.asp?SubjectArea=\&Subject=\&Section=dc\&PID=125

Anonymous (n.d. c). About EMBASE: The Excerpta Medica database. Retrieved August 11, 2005, from http://info.embase.com/embase_suite/index.shtml

Armbruster, C., Stiegler, G. M., Vcelar, B. A., Jager, W., Koller, U., Jilch, R., et al. (2004). Passive immunization with the anti-HIV-1 human monoclonal antibody (hMAb) 4E10 and the hMAb combination 4E10/2F5/2G12. Journal of Antimicrobial Chemotherapy, 54, 915-920.

Armbruster, C., Stiegler, G. M., Vcelar, B. A., Jager, W., Michael, N. L., \& Katinger, H. W. (2002). A phase I trial with two human monoclonal antibodies (hMAb 2F5, 2G12) against HIV-1. AIDS, 16, 227-233.

Bailey, J. (2005). Non-human primates in medical research and drug development: A critical review. Biogenic Amines, 19, 235-255.

Bailey, J., Knight, A., \& Balcombe, J. (2005). The future of teratology research is in vitro. Biogenic Amines, 19, 97146.

Balls, M. (1995). Chimpanzee medical experiments: Moral, legal, and scientific concerns. In Poor model man: Experimenting on chimpanzees: Proceedings of the first PACE (People Against Chimpanzee Experiments) conference on the use of chimpanzees in biomedical research. Alternatives to Laboratory Animals, 23, 607-614.

Bardsley-Elliot, A., \& Perry, C. M. (2000). Nevirapine: A review of its use in the prevention and treatment of paediatric HIV infection. Paediatric Drugs, 2, 373-407.

Bertoni, R., Sette, A., Sidney, J., Guidotti, L. G., Shapiro, M., Purcell, R., et al. (1998). Human class I supertypes and CTL repertoires extend to chimpanzees. Journal of Immunology, 161, 4447-4455.

Bigger, C. B., Brasky, K. M., \& Lanford, R. E. (2001). DNA microarray analysis of chimpanzee liver during acute resolving hepatitis $C$ virus infection. Journal of Virology, 75, 7059-7066.

Brams P., Black, A., Padlan, E. A., Hariharan, K., Leonard, J., Chambers-Slater, K., et al. (2001). A humanized antihuman CD154 monoclonal antibody blocks CD154-CD40 mediated human B cell activation. International Immunopharmacology, 1, 277-294.

Britten, R. J. (2002). Divergence between samples of chimpanzee and human DNA sequences is $5 \%$, counting indels. Proceedings of the National Academy of Science, 99, 13633-13635.

Brown, P. (2005). Blood infectivity, processing and screening tests in transmissible spongiform encephalopathy. Vox Sanguinis, 89, 63-70.

Byrne, R. W. (1998). Primate cognition. In F. L. Dolins (Ed.), Attitudes toward animals: Views in animal welfare (pp. 114-125). Cambridge, UK: Cambridge University Press.

Carlsson, H. E., Schapiro, S. J., Farah, I., \& Hau, J. (2004). Use of primates in research: A global overview. American Journal of Primatology, 63, 225-237. 
Cervenakova, L., Brown, P., Soukharev, S., Yakovleva, O., Diringer, H., Saenko, E. L., et al. (2003). Failure of immunocompetitive capillary electrophoresis assay to detect disease-specific prion protein in buffy coat from humans and chimpanzees with Creutzfeldt-Jakob disease. Electrophoresis, 24, 853-859.

Chimpanzee Sequencing and Analysis Consortium. (2005). Initial sequence of the chimpanzee genome and comparison with the human genome. 437, 69-87.

Conlee, K. M., Hoffeld, E. H., \& Stephens, M. L. (2004). A demographic analysis of primate research in the United States. Alternatives to Laboratory Animals, 32(Suppl. A), 315-322.

Conley, A. J., Kessler, J. A. II, Boots, L. J ., McKenna, P. M., Schleif, W. A., Emini, E. A., et al. (1996). The consequence of passive administration of an anti-human immunodeficiency virus type 1 neutralizing monoclonal antibody before challenge of chimpanzees with a primary virus isolate. Journal of Virology, 70, 6751-6758.

Crowe, J. E., Jr., Randolph, V., \& Murphy, B. R. (1999). The live attenuated subgroup B respiratory syncytial virus vaccine candidate RSV 2B33F is attenuated and immunogenic in chimpanzees, but exhibits partial loss of the ts phenotype following replication in vivo. Virus Research, 59, 13-22.

Curry, S. H. (2003). Why have so many drugs with stellar results in laboratory stroke models failed in clinical trials? A theory based on allometric relationships. Annals of the New York Academy of Sciences, 993, 69-74.

de Waal, F. (1982). Chimpanzee politics: Power and sex among apes. New York: Harper and Row.

de Waal, F. (1996). Good natured: The origins of right and wrong in humans and other animals. Cambridge, MA: Harvard University Press.

Evans, H. L. (1990). Nonhuman primates in behavioral toxicology: Issues of validity, ethics and public health. Neurotoxicology \& Teratology, 12, 531-536.

Feld, J. J. \& Hoofnagle, J. H. (2005). Mechanism of action of interferon and ribavirin in treatment of hepatitis C. Nature, 436, 967-972.

Fouts, R. (1995). Chimpanzee biomedical experiments: a question of efficacy. In Poor model man: Experimenting on chimpanzees: Proceedings of the first PACE (People Against Chimpanzee Experiments) conference on the use of chimpanzees in biomedical research. Alternatives to Laboratory Animals, 23, 584-591.

Gallo, R. C. (2002). Human retroviruses after 20 years: A perspective from the past and prospects for their future control. Immunological Reviews, 183, 188.

Gescuk, B. D., \& Davis, J. C. (2002). Novel therapeutic agents for systemic lupus erythematosus. Current Opinion in Rheumatology, 14, 515-521.

Glazko, G.,Veeramachaneni, V., Nei, M., \& Makalowski, W. (2005). Eighty percent of proteins are different between humans and chimpanzees. Gene, 346, 215-219.

Goh, W. C., Rogel, M. E., Kinsey, C. M., Michael, S. F., Fultz, P. N., Nowak, M. A., et al. (1998). HIV-1 Vpr increases viral expression by manipulation of the cell cycle: A mechanism for selection of Vpr in vivo. Nature Medicine, 4, 6571.

Goodall, J. (1986). The chimpanzees of Gombe: Patterns of behavior. Cambridge, MA: Belknap Press.

Goodall, J. (1995). Why is it unethical to use chimpanzees in the laboratory? In Poor model man: Experimenting on chimpanzees: Proceedings of the first PACE (People Against Chimpanzee Experiments) conference on the use of chimpanzees in biomedical research. Alternatives to Laboratory Animals, 23, 615-620.

Goodall, J. \& Bekoff, M. (2002). The ten trusts: What we must do to care for the animals we love. San Francisco: Harper SanFrancisco. 
Green, J. (1982). Asymptotic sample size for given confidence interval length. Applied Statistics, 31, $298-300$.

Grob, P. M., Cao, Y., Muchmore, E., Ho, D. D., Norris, S., Pav, J. W., et al. (1997). Prophylaxis against HIV-1 infection in chimpanzees by nevirapine, a nonnucleoside inhibitor of reverse transcriptase. Nature Medicine, 3, 665670.

Guenther, W. C. (1973). A sample size formula for the hypergeometric. Journal of Quality Technology, 5, 167-170.

Hackam, D. G., \& Redelmeier, D A. (2006). Translation of research evidence from animals to humans. Journal of the American Medical Association, 296, 1731-1732.

Hare, B., Call, J., Agnetta, B. \& Tomasello, M. (2000). Chimpanzees know what conspecifics do and do not see. Animal Behaviour, 59, 771-785.

Hepburn, T. W., Totoritis, M. C., \& Davis, C. B. (2003). Antibody-mediated stripping of CD4 from lymphocyte cell surface in patients with rheumatoid arthritis. Rheumatology, 42, 54-61.

Herodin, F., Thullier, P., Garin, D., \& Drouet, M., (2005). Nonhuman primates are relevant models for research in hematology, immunology and virology. European Cytokine Network, 16, 104-116.

Hone, D. M., DeVico, A. L., Fouts, T. R., Onyabe, D. Y., Agwale, S. M., Wambebe, C. O., et al. (2002). Development of vaccination strategies that elicit broadly neutralizing antibodies against human immunodeficiency virus type 1 in both the mucosal and systemic immune compartments. Journal of Human Virology, 5, 17-23.

Horn, J., de Haan, R. J., Vermeulen, M., Luiten, P .G., \& Limburg, M. (2001). Nimodipine in animal model experiments of focal cerebral ischemia: a systematic review. Stroke, 32, 2433-2438.

Huguenel, E. D., Cohn, D., Dockum, D. P., Greve, J. M., Fournel, M. A., Hammond, L., et al. (1997). Prevention of rhinovirus infection in chimpanzees by soluble intercellular adhesion molecule-1. American Journal of Respiratory \& Critical Care Medicine, 155, 1206-1210.

Hüssy, P., Faust, H., Wagner, J. C., Schmid, G., Mous, J., \& Jacobsen, H., (1997). Evaluation of hepatitis C virus envelope proteins expressed in E. coli and insect cells for use as tools for antibody screening. Journal of Hepatology, 26, 1179-1186.

Jha, A. (2006, June 3). Questions raised over ban on research using great apes. The Guardian. Retrieved September 19, 2006, from http://www.guardian.co.uk/science/story/0,,1789616.00.html

Jonas, S., Aiyagari, V., Vieira, D., \& Figueroa, M. (2001). The failure of neuronal protective agents versus the success of thrombolysis in the treatment of ischemic stroke: The predictive value of animal models. Annals of the New York Academy of Sciences, 939, 257-267.

Karayiannis, P. (2003). Hepatitis B virus: Old, new and future approaches to antiviral treatment. Journal of Antimicrobial Therapy, 51, 761-785.

Khanna R., Moss D. J., \& Burrows S. R. (1999). Vaccine strategies against Epstein-Barr virus-associated diseases: Lessons from studies on cytotoxic T-cell-mediated immune regulation. Immunological Reviews, 170, 49-64.

Kim .J. W., \& Wang X. W. (2003). Gene expression profiling of preneoplastic liver disease and liver cancer: A new era for improved early detection and treatment of these deadly diseases? Carcinogenesis, 24, 363-369.

Kneyber, M. C., \& Kimpen, J. L. (2002). Current concepts on active immunization against respiratory syncytial virus for infants and young children.Pediatric Infectious Disease Journal, 21, 685-696.

Knight, A. (2007). Systematic reviews of animal experiments demonstrate poor human clinical and toxicological utility. ATLA: Alternatives to Laboratory Animals. In press. 
Knight, A., Bailey, J., \& Balcombe, J. (2006a). Animal carcinogenicity studies: 1. poor human predictivity. Alternatives to Laboratory Animals, 34, 19-27.

Knight, A., Bailey, J., \& Balcombe, J. (2006b). Animal carcinogenicity studies: Implications for the REACH system. Alternatives to Laboratory Animals, 34(Suppl. 1), 139-147.

Koff, R. S. (2002). Hepatitis A, hepatitis B, and combination hepatitis vaccines for immunoprophylaxis: An update. Digestive Diseases and Science, 47, 1183-1194.

Langley, G. (2006). Next of kin: A report on the use of primates in experiments. London: British Union for the Abolition of Vivisection.

Lazzarini, L., Overgaard, K. A., Conti, E., \& Shirtliff, M. E. (2006). Experimental osteomyelitis: What have we learned from animal studies about the systemic treatment of osteomyelitis? Journal of Chemotherapy, 18, 451-460.

Leimu, R., \& Koricheva, J. (2005). What determines the citation frequency of ecological papers? Trends in Ecology \& Evolution, 20, 28-32.

Lindl, T., Voelkel, M., \& Kolar, R. (2005). Animal experiments in biomedical research. An evaluation of the clinical relevance of approved animal experimental projects. Alternatives to Animal Experimentation, 22, $143-151$.

Lindl, T., Völkel, M., \& Kolar, R. (2006). Animal experiments in biomedical research. An evaluation of the clinical relevance of approved animal experimental projects: No evident implementation in human medicine within more than 10 years. Alternatives to Animal Experimentation, 23, 111.

Mast, E. E., Alter, M. J., Holland, P. V., \& Purcell, R. H. (1998). Evaluation of assays for antibody to hepatitis E virus by a serum panel. Hepatology, 27, 857-861.

Matthews, J. B., Ramos, E., \& Bluestone, J. A. (2003). Clinical trials of transplant tolerance: Slow but steady progress. American Journal of Transplantation, 3, 794-803.

McMahon, B. J., Bruden, D. L., Petersen, K. M., Bulkow, L. R., Parkinson, A. J., Nainan, O., et al. (2005). Antibody levels and protection after hepatitis B vaccination: Results of a 15-year follow-up. Annals of Internal Medicine, 142, 333-341.

Moore, A. C., \& Hill, A.V. S. (2004). Progress in DNA-based heterologous prime-boost immunization strategies for malaria. Immunological Reviews, 199, 126-143.

Morris, E. (n.d.). Sampling from small populations. Retrieved September 20, 2006, from http://uregina.ca/ morrisev/Sociology/Sampling\%20from\%20small\%20populations.htm

Nakano, I., Fukuda, Y., Katano, Y., Nakano, S., Kumada, T., \& Hayakawa, T. (1999). Why is the interferon sensitivitydetermining region (ISDR) system useful in Japan? Journal of Hepatology, 30, 1014-1022.

Newman, R., Hariharan, K., Reff, M., Anderson, D. R., Braslawsky, G., Santoro, D., et al. (2001). Modification of the Fc region of a primatized IgG antibody to human CD4 retains its ability to modulate CD4 receptors but does not deplete CD4(+) T cells in chimpanzees. Clinical Immunology, 98, 164-174.

Obriadina, A., Meng, J. H., Ulanova, T., Trinta, K., Burkov, A., Fields, H. A., et al. (2002). A new enzyme immunoassay for the detection of antibody to hepatitis E virus. Journal of Gastroenterology \& Hepatology, 17(Suppl. 3), S360-S364.

O'Collins, V. E., Macleod, M. R., Donnan, G. A., Horky, L. L., van der Worp, B. H. \& Howells, D. W. (2006). 1,026 experimental treatments in acute stroke. Annals of Neurology, 59, 467-477. 
Ogata, N., Cote, P. J., Zanetti, A. R., Miller, R. H., Shapiro, M., Gerin, J., et al. (1999). Licensed recombinant hepatitis $B$ vaccines protect chimpanzees against infection with the prototype surface gene mutant of hepatitis $B$ virus. Hepatology, 30, 779-786.

Pancholi, P., Lee, D. H., Liu, Q., Tackney, C., Taylor, P., Perkus, M., et al. (2001). DNA prime/ canarypox boostbased immunotherapy of chronic hepatitis B virus infection in a chimpanzee. Hepatology, 33, 448-454.

Patterson, J., L., \& Carrion, R. (2005). Demand for nonhuman primate resources in the age of biodefense. Ilar Journal, 46, 15-22.

Perel, P., Roberts, I., Sena, E., Wheble, P., Briscoe, C., Sandercock, P., et al. (2007). Comparison of treatment effects between animal experiments and clinical trials: Systematic review. British Medical Journal, 334, 197.

Pound, P., Ebrahim, S., Sandercock, P., Bracken, M., \& Roberts, I. (2004). Where is the evidence that animal research benefits humans? British Medical Journal, 328, 514-517.

Regev, A. \& Schiff, E. R. (1999). Viral hepatitis.Current Opinion in Gastroenterology, 15, 234-239.

Ruvolo, M. (2004). Comparative primate genomics: The year of the chimpanzee. Current Opinion in Genetics \& Development, 14, 650-656.

Sauer, U. G. (2000). Reasons for not using primates in research. Alternatives to Animal Experimentation, 17, 217220.

Scharmann, W. (2000). The great ape project-human rights for the great anthropoid apes [German]. Alternatives to Animal Experimentation, 17, 221-224.

Seglen, P. O. (1989). Bruk av siteringsanalyse og andre bibliometriske metoder i evaluering av forskningskvalitet[Use of citation analysis and other bibliometric methods in evaluation of the quality of research]. Tidsskrift for Den Norske Laegeforening, 109, 3224-3229.

Sleasman, J. W., \& Goodenow, M. M. (2003). HIV-1 infection. Journal of Allergy \& Clinical Immunology, 111(Suppl. 2), S582-S592.

Smith, J. A., \& Boyd, K. M. (Eds.). (2002). The Boyd Group papers on the use of non-human primates in research and testing. Leicester, UK: The British Psychological Society.

Stephens, M. L. (1995). Chimpanzees in laboratories: Distribution and types of research. In Poor model man: Experimentingonchimpanzees. Proceedingsofthe firstPACE (People AgainstChimpanzee Experiments)conferenceontheuseofchimpanzeesinbiomedicalresearch.AlternativestoLaboratoryAnimals,23,579-583.

Suzuki, T., Yanai, M., Yamaya, M., Satoh-Nakagawa, T., Sekizawa, K., Ishida, S., et al. (2001). Erythromycin and common cold in COPD. Chest, 120, 730-733.

Thew, M. (2002). Are results of primate research worth the suffering it causes? Nature, 418, 273.

Tomasello, M., Call, J., \& Hare, B. (2003). Chimpanzees understand psychological states-the question is which ones and to what extent. Trends in Cognitive Sciences, 7, 153-156.

Tong, A W., \& Stone, M. J. (2003). Prospects for CD40-directed experimental therapy of human cancer. Cancer Gene Therapy, 10, 1-13.

Turner, R. B., Wecker, M. T., Pohl, G., Witek, T. J., McNally, E., St George, R., et al. (1999). Efficacy of tremacamra, a soluble intercellular adhesion molecule 1, for experimental rhinovirus infection: A randomized clinical trial. Journal of the American Medical Association, 281, 1797-1804. 
VandeBerg, J. L., Zola, S. M., Fritz, J., Lee, D., Rick, R., Thomas, J., et al. (2005). A unique biomedical resource at risk. Nature, 437, 30-32.

Varki, A., \& Altheide, T. K. (2005). Comparing the human and chimpanzee genomes: Searching for needles in a haystack. Genome Research, 15, 1746-1758.

Wang, Y.F., Brotman, B., Andrus, L., \& Prince, A. M. (1996). Immune response to epitopes of hepatitis C virus (HCV) structural proteins in HCV-infected humans and chimpanzees. Journal of Infectious Diseases, 173, 808-821.

Whiten, A., \& Byrne, R. W. (1988). Tactical deception in primates. Behavioral and Brain Sciences, 11, $233-273$.

Wong, H., Grossman, S. J., Bai, S. A., Diamond, S., Wright, M. R., Grace, J. E., Jr., et al. (2004). The chimpanzee (Pan troglodytes) as a pharmacokinetic model for selection of drug candidates: Model characterization and application. Drug Metabolism and Disposition, 32, 1359-1369.

Worm, H. C., \& Wirnsberger, G. (2004). Hepatitis E vaccines: Progress and prospects. Drugs, 64, 1517-1531.

Yang, G., D'Souza, M. P., \& Vyas, G. N. (1998). Neutralizing antibodies against HIV determined by amplification of viral long terminal repeat sequences from cells infected in vitro by nonneutralized virions. Journal of Acquired Immune Deficiency Syndromes \& Human Retrovirology, 17, 27-34.

\section{APPENDIX}

Biological Disciplines Investigated

Citing papers investigated various biological disciplines in addition to the most prominently featured hepatitis viruses, cognition, and HIV. These disciplines included the following: asthma, autism, behavior, benign prostatic hyperplasia, cancer, chronic obstructive pulmonary disease, coxsackievirus B3, Epstein-Barr virus, genetic studies, human parainfluenza virus type 3, immunology, and Kawasaki disease. In addition, the papers investigated laboratory techniques including gene expression profiling and cDNA microarray interpretation, leukemia, malaria, neuroanatomy, neurology, organ transplantation, pathology (clinical), psychology, respiratory syncytial virus, rheumatoid arthritis, rhinovirus colds, simian immunodeficiency virus, systemic lupus erythematosus, surgical techniques: cardiac allografts, toxicity: arsenic, transmissible spongiform encephalopathies, and virology: nonspecific.

cDNA microarrays, containing hundreds or thousands of microscopic spots of complementary DNA (cDNA) transcripts of mRNA templates (from which the non-coding intron sequences of the original DNA have been excised), offer the ability to examine the expression of large numbers of genes simultaneously. One possible application is the potential detection of changes in gene expression caused by toxins (toxicogenomics), well prior to more invasive end points. Allografts are tissues or organs grafted to genetically dissimilar members of the same species. 